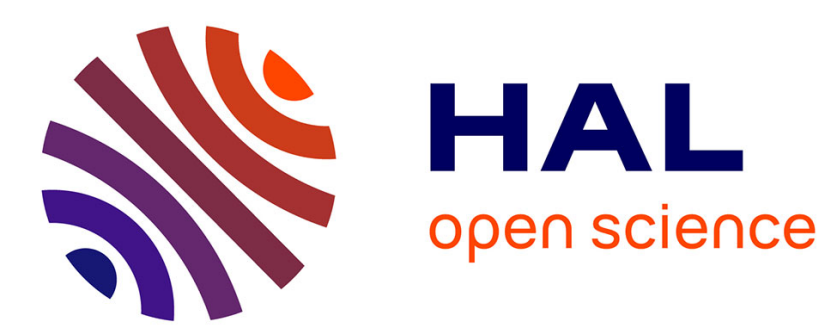

\title{
Robust control applied to minimize NOx emissions
}

Dominique Nelson-Gruel, Yann Chamaillard, Alain Charlet, Guillaume Colin

\section{To cite this version:}

Dominique Nelson-Gruel, Yann Chamaillard, Alain Charlet, Guillaume Colin. Robust control applied to minimize NOx emissions. 2014 IEEE Multi-Conference on Systems and Control, Oct 2014, Antibes, France. hal-01085875

\section{HAL Id: hal-01085875 https://hal.science/hal-01085875}

Submitted on 24 Nov 2014

HAL is a multi-disciplinary open access archive for the deposit and dissemination of scientific research documents, whether they are published or not. The documents may come from teaching and research institutions in France or abroad, or from public or private research centers.
L'archive ouverte pluridisciplinaire HAL, est destinée au dépôt et à la diffusion de documents scientifiques de niveau recherche, publiés ou non, émanant des établissements d'enseignement et de recherche français ou étrangers, des laboratoires publics ou privés.

\section{(c)(1)}

Distributed under a Creative Commons Attribution| 4.0 International License 


\title{
Robust control applied to minimize NOx emissions
}

\author{
Nelson-Gruel D., Chamaillard Y., Charlet A., Colin G.
}

\begin{abstract}
Legislation concerning pollutant emissions of diesel passenger cars is becoming increasingly restrictive, especially for nitrogen oxide (NOx) and particulate matter (PM). This article proposes to apply a CRONE control design methodology on a diesel engine in order to adapt the air-path and fuel-path of the engine and minimize NOx emissions. As the multivariable CRONE control strategies need a nominal transfer function $\left(G_{0}(s)\right)$ and some frequency response of the system $(G(s))$, several test-bench experiments and a linear identification of the system were performed. The aim of this approach was to find a decoupling and stabilizing controller for the combustion engine that minimized NOx emissions at each operating point considered and during transient of torque/engine speed. The system is a square multivariable system with three inputs: Exhaust gas recirculation valve (EGR), variable geometry turbine (VGT), and start of injection (SOI); and three outputs: mass air flow (MAF), boost pressure (Pboost) and NOx level (NOx). The CRONE control approach developed for multivariable square plants is based on the third generation scalar CRONE methodology. Fractional order transfer functions were used to define all the components of the diagonal open-loop transfer matrix, $\beta_{0}$. Optimisation gave the best fractional open-loop transfer matrix and finally, frequency domain system identification was used to find a robust controller $K(s)=G_{0}^{-1}(s) \beta_{0}(s)$. Performances of the proposed control structure were tested and validated with a number of experiments on a high dynamic test bed (NEDC driving cycle).
\end{abstract}

\section{INTRODUCTION}

Current interest in halting global warming has put pressure on the automobile industry to produce vehicles/engines that are more environmentally friendly. This has led to the development of increasingly complex engine feedback control systems. Nowadays, these control systems are mainly based on experimental data. For every type of engine, measurements concerning fuel economy and pollutant emissions must be made. These measurements include successive changes to the many parameters involved in order to cover all the operating conditions of the engine. This is very expensive and time consuming. Moreover, variations in engine-out emissions due to ageing, component drift or production tolerances pose a serious problem. One way to tackle this problem is to add control strategies on pollutant emission. This is an emerging topic driven by the development of cheap sensors that can easily measure pollutant production. [1] demonstrated the advantages of precisely controlling the quantities of $\mathrm{O}_{2}$ entering the

D. Nelson-Gruel is with the University of Orleans, Laboratoire PRISME, 8 rue Léonard de Vinci, 45000 Orleans, FRANCE (phone: +332 384946 21; e-mail: dominique-gruel-nelson@univ-orleans.fr).

G. Colin, Y. Chamaillard and A. Charlet are with the University of Orleans. cylinder to solve the pollutant emissions problem. In [2], the impact of adapting the time response between fuel-path and air-path to lower PM emissions was studied. In $[3,4]$ the authors combined air-path variables (boost pressure and exhaust gas recirculation rate, swirl valve) and a fuel-path variable (start of injection) in order to control NOx and PM emissions. A model-based observer for the engine-out emissions was used to cope with sensor lag and delay.

To solve the pollutant emissions minimisation problem using feedback, a fast and accurate sensor or a virtual sensor must be used [4, 5]. A model based on in-cylinder measurements that use the advantages of an empirical and phenomenological model was developed in [5]. This model extracts the most relevant physical phenomena and extends them by physically motivated empirical elements. The resulting model is a real-time model that shows good performances. While the topic is intensively researched, the majority of this work is based on the well-known extended Zeldovich mechanism which gives a relation to calculate the rate of NO formation using the concentration of the different gas species involved in the process. This mechanism gives good results (Fig. 1) but cannot be run in real time unless rather sweeping assumptions are made. Fig. 1 shows some results using this mechanism. The time taken to find each NOx emission level estimated value was around 10 seconds. One way to counteract the problem of designing a pollutant observer or estimator is to use a cheap pollutant emissions sensor.

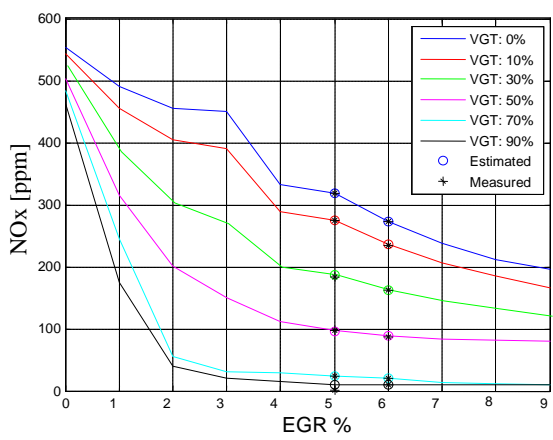

Figure 1 NOx estimated value compared to NOx measurements for different couples of EGR and VGT positions on a Diesel engine (1800rpm and 54N.m) using the extended Zeldovich Mechanism.

This study was primarily conducted to demonstrate the feasibility of a robust control during torque transient. Be able to control this variable in a robust way offers one hand the possibility of playing trajectories of NOx emissions and secondly to win some precious ppm of NOx emissions during transient of torque/engine speed. This article proposes a NOx emissions robust control strategy that uses a sensor from Siemens VD, a trademark of the Continental Corporation, 
that measures NOx levels with a fast response time (around $0.6 \mathrm{sec}$ ) but variable time-delay due to gas transportation. After section 2 in which the system identification process is presented, section 3 focuses on the robust control system design. Finally section 4 presents the performances of the proposed control structure, that were validated using test-bed experiments.

\section{SYSTEM IDENTIFICATION}

All the experiments conducted in this work were carried out on a high dynamic Engine-Dynamometer test-bed that consists of a dynamical mechanical load provided by an asynchronous machine and a Peugeot S.A. DV6, a 1.6 liter diesel engine with 4 cylinders, common-rail injection system, cooled EGR, and VGT turbocharger. The test-bed engine is equipped with a fast prototyping system based on xPCTarget from Matlab. With this module and adequate software it is possible to read the actual values of every variable calculated and measured by the ECU (Bosch, EDC 17) and modify every map and parameter contained in the ECU code. It is also possible to deploy new real-time control structures and to bypass some variables calculated or measured by the ECU.

\section{A. System description and problem formulation}

The system is a $1560 \mathrm{~cm} 3$ diesel engine with 4 cylinders and $68 \mathrm{~kW}$ at $3750 \mathrm{rpm}$. The air-path of the system is equipped with two actuators: a variable geometry turbine (VGT) and an exhaust gas recirculation valve (EGR). The fresh air coming from the atmosphere (Mass air flow: MAF) is compressed and warmed up by the compressor. The exchanger cools it down which increases the density of flow and decreases the boost pressure (pboost). The Exhaust Gas Recirculation system dilutes the fresh air entering the cylinder. The mixture of intake flow and exhaust flow decreases the mean combustion temperature, thus producing the pollutant emissions trade-off. Lower PM emissions need high temperature and oxygen in the combustion chamber where these same parameters increase the level of NOx pollutants (Fig 2).
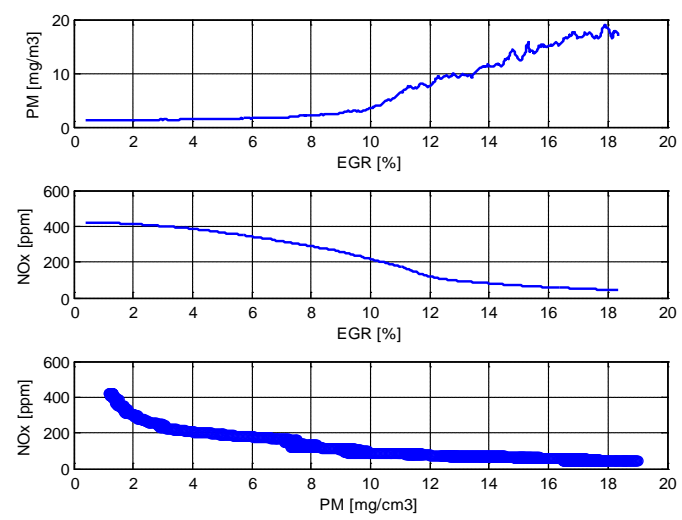

Figure 2 PM and NOx trade-off

Finally, the exhaust flow that cannot go to the intake manifold by the EGR valve flows through the turbine, and speeds it up. This energy is transmitted by a shaft to the compressor which adjusts the boost pressure. The turbine speed can be tuned by adjusting the turbine (VGT) position. The exhaust gas returns to the atmosphere and just before the NOx and PM sensors are placed. The NOx sensor used for the on-board measurement of the NOx concentration (Siemens-VDO, measuring range between 0 and 1500 ppm) is a smaller and cheaper device whose working principle is briefly explained in [5-8].

As described above, NOx emissions are essentially defined by the local temperature trajectory and by the availability of oxygen in the cylinder, which are influenced by the intake conditions, the burn gas rate (air-path variables) and the SOI (fuel-path variable). It was shown in $[9,4]$ that NOx control is clearly a multivariable control problem with a high coupling phenomenon that is provided by coupling between the air and fuel-path variables used to control this output.

\section{B. System identification}

The frequency-domain control-system-design (CSD) approach used in this work requires high fidelity linear dynamic models that approximate the underlying dynamics of the engine. Thus, a frequency domain system identification methodology was used to obtain a linear timeinvariant model that approximates the dynamics of the diesel engine. The studied system is a MIMO system with three inputs and three outputs $(3 \times 3)$.

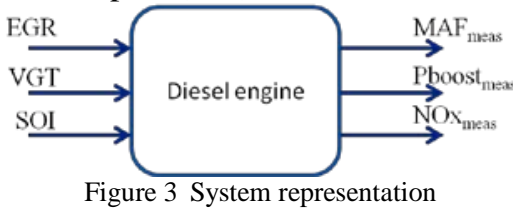

To identify the system described Fig. 3, some step and multisine signals are used. A multisine is a combination of sinusoids with various frequencies. The equation of this signal is written:

$$
u(t)=\sum_{k=1}^{N} A_{k} \cos \left(2 \pi f_{k} t+\varphi_{k}\right)
$$

where:

- N: number of harmonics,

- $f_{k}$ : harmonic frequency,

- ${ }_{\varphi k}$ : initial phase of ea ${ }_{c h}$ harmonic,

- ${ }_{A k}$ : harmonic amplitude.

Step signals are first used to define the bandwidth where the outputs can be excited (range of $f_{k}$ ) and the acceptable amplitude $A_{k}$ is chosen in such a way that the system gives a linear response. The multisine excitation signal is chosen with a sampling time of $200 \mathrm{~Hz}$ and a frequency range from $0.1 \mathrm{~Hz}$ to $20 \mathrm{~Hz}$. After that, using the superposition theorem, the multisine signal is applied on the system to find the frequency response of each input-output transfer function of the system. This process is repeated for fourteen operating points on the overall range of operating points (Fig. 4). Fig. 5 shows the results obtained with this identification method applied on fourteen operating points. 


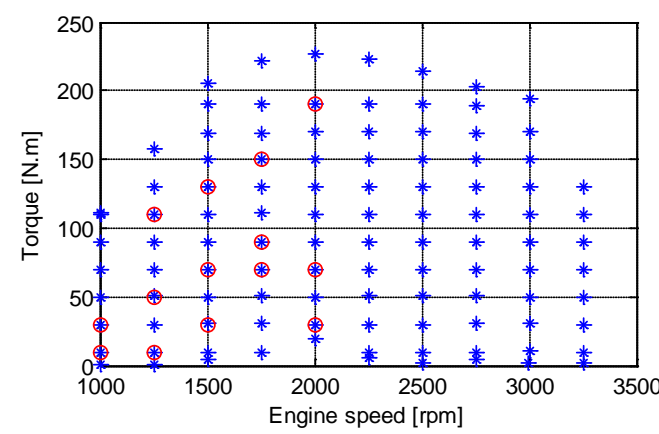

Figure 4 Speed-Torque map of the diesel engine (blue stars) and fourteen operating points used to identify the system (red circle)

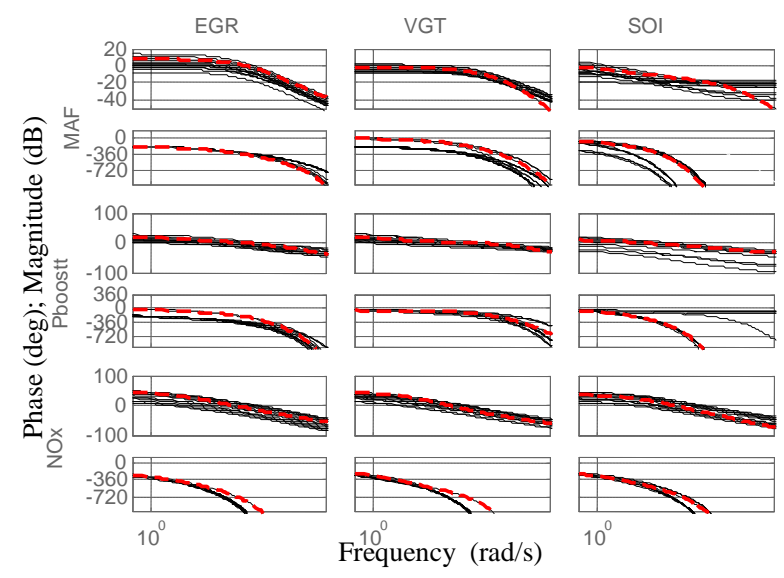

Figure 5 Bode diagram of the real system around fourteen operating points (black solid line) and the defined nominal plant (red dash-dash line)

The frequency domain identification provides a nonparametric model (Fig. 5). The phase deviation and gain variation observed demonstrate that our system is a nonlinear one that can be approximated at each operating point by a matrix of linear time-delay transfer function. A parametric identification of one of the fourteen operating points gives the following matrix:

$$
G_{0}(s)=\left[\begin{array}{ccc}
g_{11}(s) & \cdots & g_{13}(s) \\
\vdots & \ddots & \vdots \\
g_{31}(s) & \cdots & g_{33}(s)
\end{array}\right],
$$

with $g_{i j}(s)=h_{i j}(s) e^{-L_{i j} s}, h_{i j}(s)$ a strictly proper timedelay free transfer function and $L_{i j} \in \mathbb{R}^{*+}$.

The bode diagram of this matrix transfer function called the nominal plant is also presented on Fig. 5 in red.

\section{ROBUST CONTROL IN DIESEL ENGINES}

The robust control strategies proposed in this section used the CRONE control methodology [10] and more precisely its development on a time-delay multivariable system [11, 12]. The aim of the multivariable (MIMO) CRONE control approach is to robustify closed-loop dynamic performance through robustness of the damping factor or the resonant control peaks, when plant parameters vary. Contrary to some methods, CRONE control and design does not deal with robustness of the closed loop bandwidth and thus limits the control effort. The CRONE CSD is based on the common unity-feedback configuration, Fig. 6.

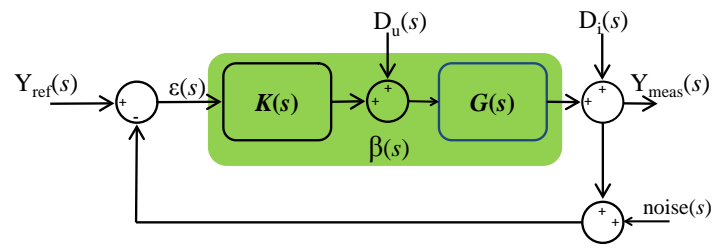

Figure 6 Common CRONE control-system diagram

The CRONE methodology used consists in finding the nominal diagonal and optimal open-loop transfer matrix with 3 fractional order transfer elements [10, 13]:

$$
\beta_{0}(s)=G_{0}(s) K(s)=\left[\begin{array}{ccc}
\beta_{011}(s) & \cdots & 0 \\
\vdots & \ddots & \vdots \\
0 & \cdots & \beta_{033}(s)
\end{array}\right] .(3)
$$

Each element, $\beta_{0 i i}(s)$, of the diagonal open-loop matrix $\beta_{0}(s)$ is based on the third generation CRONE single-input single-output methodology [10]. The principle of this methodology is to optimize the parameters of the nominal open-loop transfer function $\beta_{0}(s)$ that includes band-limited complex fractional order integration over a frequency range $\left[\omega_{l}, \omega_{h}\right]$. The complex fractional order, $n=a+\mathrm{i} b$, enables a straight line of any direction to be created in the Nichols chart which is called the generalized template (Fig. 7).

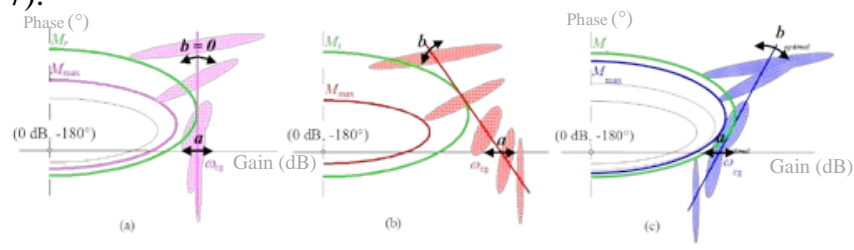

Figure 7 (a) template with real fractional order, (b) template with complex fractional order, (c) optimal template

The open-loop transfer functions $\beta_{0 i i}(s)$ around the resonant frequency, $\omega_{\mathrm{r}}$ is defined by:

$$
\beta_{0 i i}=\beta_{\mathrm{li}}(s) \beta_{\mathrm{mi}}(s) \beta_{\mathrm{hi}}(s),
$$

where:

$\beta_{m i}(s)=C^{\operatorname{sign}(b)}\left(\frac{1+s / \omega_{\mathrm{h}}}{1+s / \omega_{1}}\right)^{a} \times\left(\mathfrak{R} e_{/ \mathrm{i}}\left(\left(C_{\mathrm{g}} \frac{1+s / \omega_{\mathrm{h}}}{1+s / \omega_{1}}\right)^{\mathrm{i} b}\right\}\right)^{-\operatorname{sign}(b)}$,

With

- $\beta_{\mathrm{li}}(s)=C_{\mathrm{li}}\left(\frac{\omega_{l}}{s}+1\right)^{n_{\mathrm{li}}}$, order $n_{\mathrm{li}}$ fixes the accuracy of each closed-loop,

- $\beta_{\mathrm{h} i}(s)=C_{\mathrm{h} i}\left(\frac{s}{\omega_{h}}+1\right)^{n_{\mathrm{h} i}}$, order $n_{\mathrm{h} i}$ permits the elements of the controller to be proper,

$-C_{g}=\left(\frac{1+\left(\frac{\omega_{\mathrm{r}}}{\omega_{l}}\right)^{2}}{1+\left(\frac{\omega_{\mathrm{r}}}{\omega_{h}}\right)^{2}}\right)^{\frac{1}{2}}$

- The gains $C, C_{\mathrm{l} i}$ and $C_{\mathrm{h} i}$ are such that $\omega_{\mathrm{r}}$ is the closed-loop resonant frequency $\left(K_{i}=C . C_{\mathrm{li}} \cdot C_{\mathrm{h} i}\right)$. 
Considering (3) nominal sensitivity, complementary sensitivity, input sensitivity and input-disturbance sensitivity function transfer matrices are:

$$
\begin{gathered}
\mathrm{S}_{0}(s)=\left[I+\beta_{0}(s)\right]^{-1}=\operatorname{diag}\left[\frac{1}{\left(1+\beta_{0 i i}(s)\right)}\right]_{1 \leq i \leq 3} \\
\mathrm{~T}_{0}(s)=\left[I+\beta_{0}(s)\right]^{-1} \beta_{0}(s)=\operatorname{diag}\left[\frac{\beta_{0 i i}(s)}{\left(1+\beta_{0 i i}(s)\right)}\right]_{1 \leq i \leq 3} \text {,(7) } \\
\mathrm{S}_{\mathrm{U} 0}(s)=K(s)\left[I+\beta_{0}(s)\right]^{-1}=K(s) \mathrm{S}_{0}(s) \\
\mathrm{S}_{\mathrm{i} 0}(s)=\left[I+\beta_{0}(s)\right]^{-1} G(s)=\mathrm{T}_{0}(s) K^{-1}(s)
\end{gathered}
$$

For plants other than the nominal, the closed-loop transfer matrices $T(s)$ and $S(s)$ are no longer diagonal. Each diagonal element $T_{i i}(s)$ and $S_{i i}(s)$ can be interpreted as a closed-loop transfer function resulting from a scalar open-loop transfer function $\beta_{i i}(s)$ called equivalent open-loop transfer function:

$$
\beta_{i i}(s)=\frac{T_{i i}(s)}{1-T_{i i}(s)}=\frac{1-S_{i i}(s)}{S_{i i}(s)} .
$$

Figure 7 shows that the resonant peak $M_{r}$ variation of the complementary sensitivity function is reduced by optimizing the position of the generalized template in the Nichols chart (Fig. 7b and 7c). The robustness cost function is given by

$$
J=\left(\sup \left|M_{\mathrm{r}}\right|-\inf \left|M_{\mathrm{r}}\right|\right)^{2},
$$

whith:

$$
\begin{aligned}
& -\sup \left|M_{\mathrm{r}}\right|=\max _{G} \sup _{\omega}\left(T_{i i}(j \omega)\right), \\
& -\inf \left|M_{\mathrm{r}}\right|=\min _{G} \sup _{\omega}\left(T_{i i}(j \omega)\right),
\end{aligned}
$$

where $G$ is the set of all the operating points of the diesel engine, and while respecting the frequency-domain inequalities below for $\omega \in \mathbb{R}^{+}$and $i, j \in N$ :

$$
\begin{gathered}
\sup _{G}\left|T_{i j}(\mathrm{j} \omega)\right| \leq T_{i j_{\mathrm{up}}}(\omega), \\
\inf _{G} \mid T_{i j}(\mathrm{j} \omega) \geq T_{i j_{\text {low }}}(\omega), \\
\sup _{G}\left|S_{i j}(\mathrm{j} \omega)\right| \leq S_{i j \mathrm{up}}(\omega), \\
\sup _{G} \mid K S_{i j}(\mathrm{j} \omega) \leq K S_{i j_{\mathrm{up}}}(\omega), \\
\sup _{G} \mid S G_{i j}(\mathrm{j} \omega) \leq S G_{i j_{\mathrm{up}}}(\omega) .
\end{gathered}
$$

As the uncertainties are taken into account by the least conservative method, a non-linear optimization method must be used to find the optimal values of the independent parameters of the fractional open-loop, and consequently to find an optimal placement of the equivalent open-loop frequency response.

\section{A. Decoupling and optimized controller}

Let $G_{0}$ be the nominal plant transfer matrix and considering (3), the aim of the CRONE control approach for MIMO plants is to parameterize $\beta_{0}(s)$ to satisfy the following four objectives:

- perfect decoupling for the nominal plant,

- accuracy specifications at low frequencies,
- required nominal stability margins of the closed loops (behaviours around the required cut-off frequencies),

- specifications on the $n$ control efforts at high frequencies.

As $G_{0}$ is not diagonal, the problem is to find a decoupling and stabilizing controller $K(s)$. This controller exists if and only if the following hypotheses are verified:

$$
\begin{gathered}
H_{1}:\left[G_{0}(s)\right]^{-1} \text { exists, } \\
H_{2}: Z_{+}\left[G_{0}(s)\right] \cap P_{+}\left[G_{0}(s)\right]=0,
\end{gathered}
$$

where $Z_{+}\left[G_{0}(s)\right]$ and $P_{+}\left[G_{0}(s)\right]$ indicate the positive real part zero and pole sets.

Once $\beta_{0}(s)$ has been optimized, the controller is given by:

$$
\boldsymbol{K}(s)=\mathbf{G}_{0}^{-1}(s) \boldsymbol{\beta}_{0}(s),
$$

where $\mathbf{G}_{0}^{-1}(s)$ is the inverse of the nominal plant $\mathbf{G}_{0}(s)$. In [12], the author demonstrates that when $G_{0}(s)$ is defined by (2) $\mathbf{P}(s)$ can be written:

$$
\mathbf{G}_{0}^{-1}(s)=\mathbf{P}(s)=\left[\begin{array}{ccc}
P_{11}(s) e^{\gamma_{11} s} & \cdots & P_{1 n}(s) e^{\gamma_{13} s} \\
\vdots & \ddots & \vdots \\
P_{31}(s) e^{\gamma_{31} s} & \cdots & P_{n n}(s) e^{\gamma_{33} s}
\end{array}\right],
$$

where $P_{i j}(s)$ is the non-zero transfer function and $\gamma_{i j} \in \mathbb{R}^{*+}$. Each element of the controller is obtained from relations (19) and (20):

$$
K_{i j}(\mathrm{j} \omega)=P_{i j}(\mathrm{j} \omega) e^{\gamma_{i j} \mathrm{j} \omega} \beta_{0 j j}(\mathrm{j} \omega) .
$$

To make the controller achievable and the closed loop fully stable for unstable and under-damped systems with nonminimum phase (RHP zeros or time-delays), the open-loop transfer function must include a calculated nominal timedelay, under-damped modes and right half plane zeros and poles of $G_{0}(s)$ and $G_{0}^{-1}(s)[11,12]$.

\section{APPLICATION : EXPERIMENTAL RESULTS}

The issue of minimizing NOx emissions can be relaxed if a NOx sensor is integrated into a feedback loop. In [4] a model-based observer and classical proportional and integral controller are used for feedback NOx emissions. In [8] a multivariable feedback controller of NOx emissions and air/fuel ratio (PM indicator) was designed. The controlled inputs used were EGR valve and injection timing. In [14] the control design objective was to coordinate EGR and VGT actuators to fully use their effect on engine emission performance. Air/fuel ratio and burned gas fraction in the intake manifold were regulated to meet a new optimum equilibrium. In this section, the robust multivariable controller for NOx emissions is presented. The performance of the proposed control structure has been tested and validated with a number of load-step experiments and with the NEDC driving cycle. The studied diesel engine is a MIMO time-delay system with three inputs and three outputs (3×3). 


$$
\left[\begin{array}{l}
Y_{1} \\
Y_{2} \\
Y_{3}
\end{array}\right]=\left[\begin{array}{lll}
G_{11} & G_{12} & G_{13} \\
G_{21} & G_{22} & G_{23} \\
G_{31} & G_{32} & G_{33}
\end{array}\right]\left[\begin{array}{l}
U_{1} \\
U_{2} \\
U_{3}
\end{array}\right],
$$

$G_{i 1}$ : from EGR input (\%) to respectively MAF (kg/h) for $i=1$, Pboost (mbar) for $i=2$ and NOx level for $i=3$,

$G_{i 2}$ : from VGT input (\%) to respectively MAF (kg/h) for $i=1$, Pboost (mbar) for $i=2$ and NOx level for $i=3$,

$G_{i 3}$ : from SOI input $\left({ }^{\circ} \mathrm{CA}\right)$ to respectively MAF $(\mathrm{kg} / \mathrm{h})$ for $i=1$, Pboost (mbar) for $i=2$ and NOx level for $i=3$.

The determinant of $\mathbf{G}_{0}(s)$ has a right half plane pole $(+15.597)$ that thus needs to be included (as zeros) in $\beta_{011}(s)$, $\beta_{022}(s)$ and $\beta_{033}(s)$ for the stabilization of the $\mathbf{C S}(\mathrm{s})$ transfer function matrix. Low frequency accuracy specifications are ensured by $n_{1}=1$ for $\beta_{011}(s), n_{1}=1$ for $\beta_{022}(s)$ and $n_{1}=1$ for $\beta_{033}(s)$. The high-frequency control efforts are limited with $n_{\mathrm{h}}=4$ for $\beta_{011}(s), n_{\mathrm{h}}=3$ for $\beta_{022}(s)$ and by $n_{\mathrm{h}}=4$ for $\beta_{033}(s)$. The nominal resonant peak for $\beta_{011}(\mathrm{~s})$ is $0, \mathrm{M}_{\mathrm{r} 022}=0$ for $\beta_{022}(s)$ and $\mathrm{M}_{\mathrm{r} 033}=0.5$ for $\beta_{033}(s)$.

The highest value of the resonant peak of each $\left|T_{i i}(\mathrm{j} \omega)\right|$ (related to the overshoot specification) must not exceed $3 \mathrm{~dB}$. Using cost function (11) to solve this control problem, some frequency-domain constraints of (12) to (16) are very simply defined:

$$
\begin{aligned}
& -T_{i i \mathrm{u}}(\omega)=+3 \mathrm{~dB}, \\
& -S_{i i \mathrm{u}}(\omega)=+6 \mathrm{~dB} \text { (for a } 0.5 \text { modulus margin). }
\end{aligned}
$$

The nominal plant and the whole set of the measured frequency-responses are used to optimize at the same time the parameters of $\beta_{011}(s), \beta_{022}(s)$ and $\beta_{033}(s)$. For the MAF open-loop $\beta_{011}(\mathrm{~s})$, the optimal parameters are: $Y_{\mathrm{r}}=5 \mathrm{~dB}$, $\omega_{\mathrm{r}}=0.1 \mathrm{rad} / \mathrm{s}, \omega_{1}=0.01 \mathrm{rad} / \mathrm{s}, \omega_{1}=10 \mathrm{rad} / \mathrm{s}, \omega_{\mathrm{h}}=100 \mathrm{rad} / \mathrm{s}$, $a_{+1}=-1$, and $b_{+1}=0$. Parameters $a_{0}=1.10, b_{0}=-0.51$ and $K_{1}=10.05$ are computed from these optimized values. For the Pboost open-loop $\beta_{022}(\mathrm{~s})$, the optimal parameters are: $Y_{\mathrm{r}}=$ $3 \mathrm{~dB}, \omega_{\mathrm{r}}=0.01 \mathrm{rad} / \mathrm{s}, \omega_{1}=0.005 \mathrm{rad} / \mathrm{s}, \omega_{\mathrm{h}}=5 \mathrm{rad} / \mathrm{s}$. Thus $a_{0}=$ $1.32, b_{0}=-0.60$ and $K_{2}=10$. For the NOx open-loop $\beta_{033}(s)$, the optimal parameters are: $Y_{\mathrm{r}}=8 \mathrm{~dB}, \omega_{\mathrm{r}}=0.05 \mathrm{rad} / \mathrm{s}, \omega_{1}=$ $0.01 \mathrm{rad} / \mathrm{s}, \omega_{\mathrm{h}}=100 \mathrm{rad} / \mathrm{s}$. Thus $a_{0}=1.22, b_{0}=-0.08$ and $K_{3}=1.41$. Figure 8 shows the optimized open-loop frequency response and Fig. 9 shows the nominal and reparametered magnitude of the complementary sensitivity matrix transfer function. The final values of the cost function are respectively $1.3 \mathrm{~dB}, \quad 0.6 \mathrm{~dB}, 1 \mathrm{~dB}$ and all sensitivity constraints are met
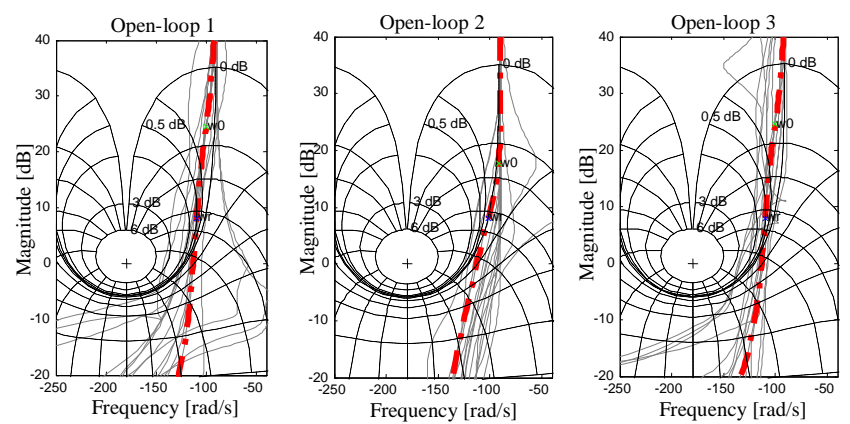

Figure 8 Optimized nominal (red dash-dot line) and equivalent open-loop frequency responses (grey solid line)
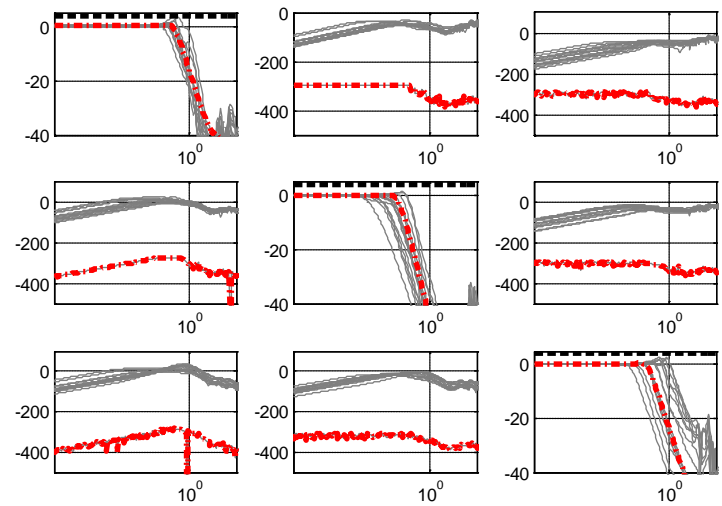

Figure 9 Nominal ( red dash-dot line) and perturbed gains (grey solid line) of $\mathrm{T}$ highest value of the resonant peak of each $\left|\mathrm{T}_{i i}(\mathrm{j} \omega)\right|$ ( black dash-dash line)

Figure 10 presents the frequency response of the controller K(s) obtained from (19).

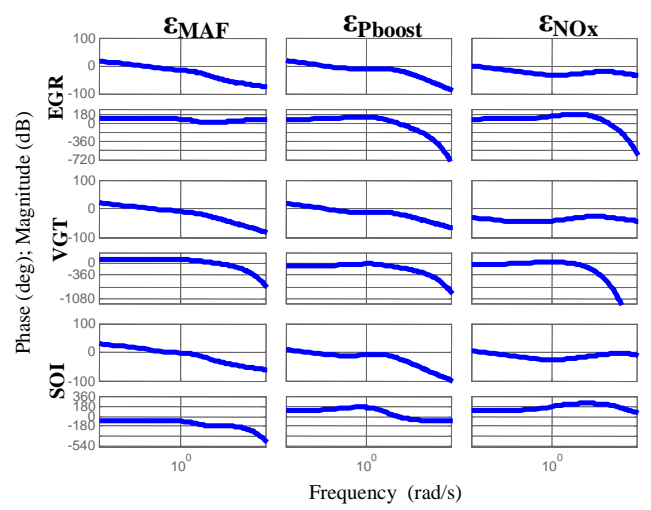

Figure 10 MIMO controller frequency response

The designed controller was assessed with some time domain tests on the test-bed. The proposed controller is compared to the results obtained with a conventional diesel engine control (standard ECU control). The standard ECU control consists of two single input single output controllers. The first one control MAF with EGR valve and the second one control Pboost with VGT. The two loops of the standard ECU controller have the same bandwidth of the first two loops of the robust controller designed. Figure 11 and 12 show some load-steps that validated the robust behavior of the control structure. 

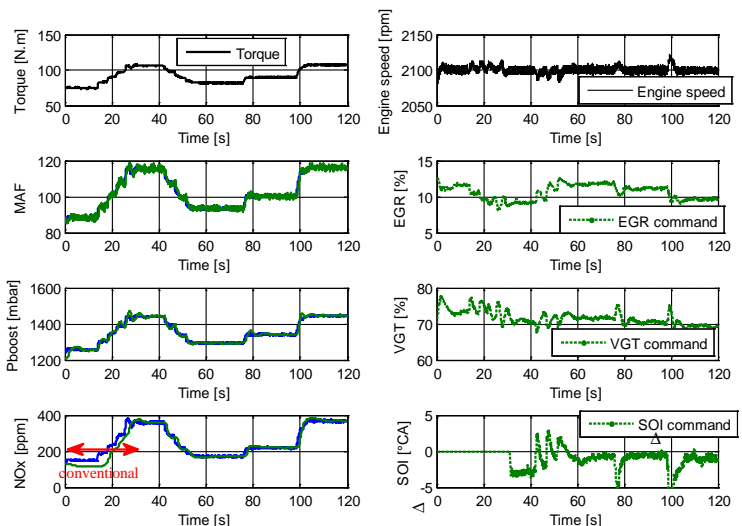

Figure 11 For a variation of torque: MAF, pboost and NOx emissions are measured (green measures, blue setpoints)
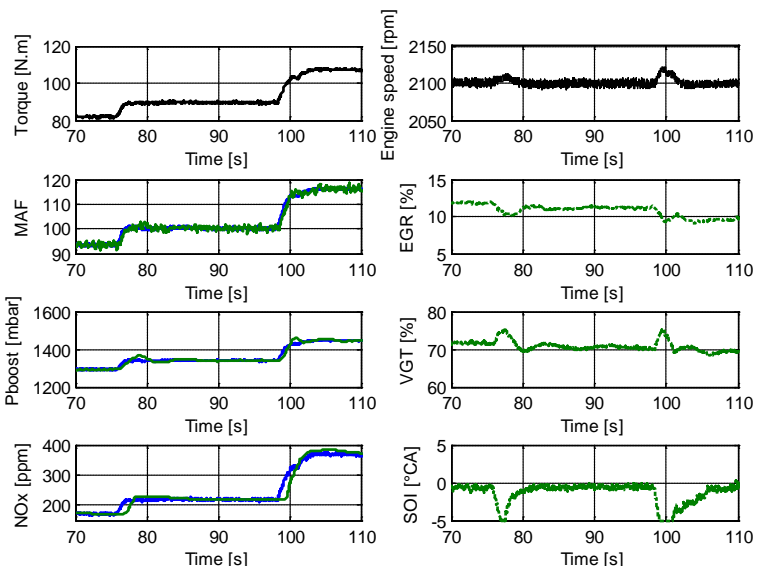

Figure 12 Zoom on 2 load-steps: MAF, Pboost and NOx emissions are measured (green measures, blue setpoints)
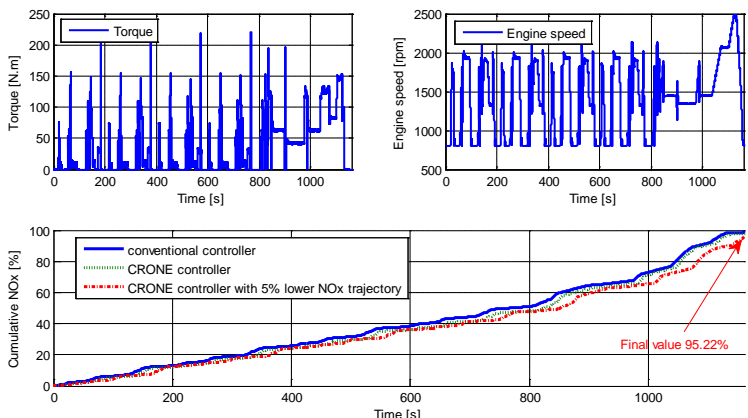

Figure 13 Normalized cumulative emissions during an NEDC driving cycle: Standard ECU control (blue solid line), CRONE robust control (green

dash-dash line) and CRONE robust control with NOx setpoint trajectory fixed at 5\% lower than the "conventional”NOx level (red dash-dot line)

Figure 13 focuses on the validation of NOx control during a driving cycle. The NOx setpoint trajectory was fixed at 5\% lower than the NOx level obtained with a conventional diesel engine controller. Results obtained during an NEDC driving cycle proved the feasibility of the proposed robust controller.

\section{CONCLUSION}

The CRONE methodology has been applied to feedback NOx emissions. To treat this kind of plant, a square $3 \times 3$ time-delay multivariable system, some time-delay and right half plane poles of $G_{0}$ or its inverse must be introduced in each open-loop. A PSA DV6 diesel engine was used to improve the proposed approach. The time domain data show that the CRONE control approach successfully states the robust stability of the closed-loops, the robust decoupling and actually minimizes the amount of NOx produced. As mentioned in section 2, reduce the amount of NOx produced leads irrevocably to increase the amount of PM produced. The next step of this work would be to design a control law that would take into account these two variables at the same time.

\section{REFERENCES}

[1] C. Bessai, R. Gratzke, "Emissions reduction potential of closed-loop intake oxygen control” European control conference, July 2013, Zurich.

[2] S. Zentner, E. Schäfer, C. Onder, L. Guzzella, "Model-based injection and EGR adaptation and its impact on transient emissions and drivability of a diesel engine” IFAC Advances in Automotive Control, Sept. 2013, Tokyo.

[3] F. Tschanz, A. Amstutz, C. Onder, L. Guzzella, "Control of diesel engines using NOx emission feedback” SAGE International Journal of engine research, 2013.

[4] F. Tschanz, A. Amstutz, C. Onder, L. Guzzella, "Feedback control of particulate matter and nitrogen oxide emissions in diesel engines" IFAC Control engineering practice, 2013.

[5] N. Kato, Y. Hamada, and H. Kurachi, "Performance of thick film NOx sensor on diesel and gasoline engines.” SAE paper 970858, 1997.

[6] N. Kato, H. Kurachi, and Y. Hamada, “Thick film Zr02 NOx sensor for the measurement of low NOx concentration." SAE, 1998.

[7] N. Kato, K. Nakagaki, and N. Ina, "Thick film ZrO2 NOx sensor." SAE, 1996

[8] E. Alfieri, Emission-controlled diesel engines PhD thesis, 2009.

[9] A. Helmantel, J. Somhorst, I. Denbratt "Visualization of the effects of post injection and swirl on the combustion process of a passenger car common rail DI diesel engine" ASME conference proceedings, pp.631-640, 2003.

[10] A. Oustaloup “La commande CRONE, 2nd edition”, HERMES, 1999.

[11] D. Nelson-Gruel, "Extension de la commande CRONE multivariable aux systèmes non carrés : application à un système d'air de moteurs essence et diesel". PhD thesis, 2009.

[12] D. Nelson Gruel, P. Lanusse, A. Oustaloup "Robust control design for multivariable plants with time-delays”. Chemical Engineering Journal, 2008.

[13] P, Lanusse, A. Oustaloup, B. Mathieu, "Robust control of LTI square MIMO plants using two CRONE control design approaches”, IFAC Symposium on Robust Control Design, Prague, Czech Republic, 2000.

[14] A. Stefanopoulou, I. Kolmanovsky, J. S. Freudenberg, "Control of variable geometry turbocharged diesel engines for reduced emissions" IEEE Transactions on control systems technology, Vol 8, N4, 2000. 